\title{
Hospital Safety Climate, Psychosocial Risk Factors and Needlestick Injuries in Japan
}

\author{
Derek R. SMITH ${ }^{1 *}$, Takashi MUTO², Toshimi SAIRENCHI ${ }^{2}$, Yumiko ISHIKAWA ${ }^{3}$, \\ Shizue SAYAMA ${ }^{4}$, Atsushi YOSHIDA ${ }^{5}$ and Maureen TOWNLEY-JONES ${ }^{6}$ \\ ${ }^{1}$ WorkCover New South Wales Research Centre of Excellence, School of Health Sciences, Faculty of Health, \\ University of Newcastle, Ourimbah 2258, Australia \\ ${ }^{2}$ Department of Public Health, Dokkyo Medical University School of Medicine, Tochigi, Japan \\ ${ }^{3}$ School of Nursing, Dokkyo Medical University, Tochigi, Japan \\ ${ }^{4}$ Department of Nursing, Dokkyo Medical University Hospital, Tochigi, Japan \\ ${ }^{5}$ Division of Infection Control, Clinical Laboratory Medicine, Dokkyo Medical University Hospital, Tochigi, \\ Japan \\ ${ }^{6}$ School of Mathematical and Physical Sciences, Faculty of Science and Information Technology, University \\ of Newcastle, Ourimbah, Australia
}

Received March 12, 2009 and accepted July 22, 2009

\begin{abstract}
To investigate the interactions between safety climate, psychosocial issues and Needlestick and Sharps Injuries (NSI), a cross-sectional study was undertaken among nurses at a university teaching hospital in Japan (89\% response rate). NSI were correlated with various aspects of hospital safety climate including supporting one another at work, the protection of staff against blood-borne diseases being a high management priority, managers doing their part to protect staff from blood-borne disease, having unsafe work practices corrected by supervisors, having the opportunity to use safety equipment to protect against blood-borne disease exposures, having an uncluttered work area, and having minimal conflict within their department. In conclusion, this study has demonstrated the importance of hospital safety climate in Japanese health care practice, particularly its relationship with NSI. Although the provision of safer devices remains critical in preventing injuries, ensuring a positive safety climate will also be essential in meeting these important challenges for nurses' occupational health.
\end{abstract}

Key words: Needlestick and sharps injuries, Safety climate, Risk, Prevalence, Japan, Nurse

\section{Introduction}

Needlestick and Sharps Injuries (NSI) represent an important workplace issue in contemporary health care. They form part of a broader area known as Percutaneous Exposure Incidents (PEI), a term referring to cutaneaous exposures and mucous membrane exposures to blood and serum ${ }^{1)}$. Although NSI are regularly experienced by Health Care Workers (HCW) of all disciplines, they are known to be especially common in the nursing profes$s^{2}{ }^{2)}$, including student nurses ${ }^{3)}$. In one Australian study for example ${ }^{4)}$, NSI as a cause of injury among nurses was

*To whom correspondence should be addressed.

E-mail: derek.smith@newcastle.edu.au exceeded only by musculoskeletal injuries. In a study of Chinese nurses ${ }^{5}$, almost all had experienced at least one NSI in their professional lifetime. Among non-hospital based nurses in the United States (US) the prevalence of NSI has been demonstrated at $9 \%$ in a given year ${ }^{6}$.

Experiencing an NSI at work can be traumatic for $\mathrm{HCW}$, although its long-term sequelae varies. Injuries from contaminated devices for example, represent a key vector for the transmission of blood-borne diseases between patients and $\mathrm{HCW}$, and vice versa. The risk to hospital staff is not evenly distributed either, with previous research from Taiwan finding that $65 \%$ of all possible seroconversions would occur among nurses ${ }^{7)}$. Acute blood-borne infections and seroconversion following an NSI has been reported among $\mathrm{HCW}$ in various countries. 
The seroconversion rate for Hepatitis C Virus (HCV) in a Japanese hospital, for example, was previously shown to be $3 \%{ }^{8}$, while a study from Turkey ${ }^{9}$ revealed that approximately $8 \%$ of nurses surveyed were already carrying this disease.

In recent years, psychosocial and organizational factors have been increasingly associated with NSI risk across a variety of studies. Factors can include high mental pressure, time pressure, feeling fatigued after work, inadequate staffing levels, and many others ${ }^{10-12)}$. In Japan psychosocial risk factors have been associated with NSI among medical residents ${ }^{13)}$ and hospital nurses ${ }^{10)}$. Organizational climate has important repercussions for nurses' occupational health outcomes ${ }^{14)}$, with safety climate having been shown to affect nurses' compliance with universal precautions ${ }^{15}$. Although the dimensions of safety climate have been studied in Japanese HCW to some extent ${ }^{16)}$, research has mostly focussed on patient safety ${ }^{17)}$, rather than NSI.

Safety climate itself represents a complicated area to investigate in occupational health, however, as many different factors are known to influence $i^{18}{ }^{18}$. Common features of safety climate are known to exist ${ }^{19)}$, and as a result, various safety climate scales have been developed and examined ${ }^{20-22)}$. Safety climate research with respect to NSI was somewhat simplified in the year 2000, when Gershon and colleagues devised a brief 20-item Hospital Safety Climate Scale (HSCS) ${ }^{23}$, incorporating 6 dimensions of safety climate based on their previous research. The validity and reliability of the HSCS as an indicator of safety climate in health care settings has been recently demonstrated ${ }^{24)}$. Given that Japanese HCW are known to suffer from $\mathrm{NSI}^{25}$ ) and that they also incur some unique, culturally-specific NSI risks ${ }^{26}$, it was considered necessary to investigate interactions between hospital safety climate, psychosocial factors and NSI within a Japanese setting by using a modified and translated version of the HSCS.

\section{Methods}

This study involved an anonymous cross-sectional survey of all nurses from a large, university teaching hospital in central Japan. Ethical approval was obtained from a hospital ethics committee prior to the study being undertaken. Our survey instrument was based on Gershon and colleagues' aforementioned Hospital Safety Climate Scale $^{23)}$. All 20 questions from this scale were initially translated into Japanese by a bilingual medical professional. An expert panel of nursing and medical professionals then assessed the Japanese version for accuracy, clarity and readability. Minor changes were made where appropriate, after which time the questionnaire was back- translated into English by a bilingual Japanese nurse and assessed against the original document. Similar to the original HSCS, our Japanese version used Likert-scale answers ${ }^{27)}$, although the five categories of 'Strongly Disagree', 'Disagree', 'No Opinion', 'Agree' or 'Strongly Agree' were reduced to four by omitting the middle response. This step was deemed particularly necessary as cultural differences are known to affect responses to Likert Scale questions ${ }^{28)}$, with Japanese and Chinese students being previously shown to cluster their answers around the midpoint ${ }^{29)}$. Other sections of the HSCS were also amended for cultural reasons. Questions from the original HSCS which focused on HIV, for example, were changed to the more generic category of 'Blood-Borne Diseases', due to a proportionately lower prevalence of HIV in Japan.

Fifteen questions relating to psychosocial risk factors were also included in our survey tool, all of which were based on previous research in this field ${ }^{30-32)}$. Questions focussed on work support, mental pressure, time pressure, work responsibility and many others. NSI questions were based on similar research previously conducted across a variety of countries ${ }^{33-35)}$. Questions focussed on the type of device which caused the injury, the number of times nurses had received such an injury in the previous 12month, whether the item had been used on a patient prior to injury and whether nurses had officially reported to management any NSI they sustained. Additional questions focussed on demographic and workplace items, such as age, gender, weekly working hours and length of employment as a nurse. As with the HSCS, all questions were translated and assessed by an expert panel of nursing and medical professionals, before being back-translated and assessed against the original document.

Questionnaires were distributed in late 2008 and collected within a 2-wk period. Informed consent was implied by the voluntary completion and return of questionnaires. All data was entered into a spreadsheet and analysed by statistical software (JMP, Version 8). Statistical analysis included prevalence rates for Likertscale responses to the HSCS, as well as NSI sustained, cause of injury and reporting behaviour following the incident. To facilitate statistical analysis, HSCS items were collapsed into dichotomous (agree/disagree) responses. Chi-squared analysis was then undertaken to examine potential relationships between the dimension of HSCS and NSI devices.

\section{Results}

A total of 1,027 questionnaires were distributed, although 31 nurses were on leave at the time of our study, leaving 996 for inclusion. Among them, 882 question- 
naires were returned, giving a response rate of $88.6 \%$. Eighteen incomplete questionnaires were then excluded, leaving 864 for the final analysis. Most nurses (93.9\%) were female, with an average age of $32 \mathrm{yr}$ (SD $9.1 \mathrm{yr}$ ). Females were on average, slightly older than the males (32 versus $29 \mathrm{yr}$ ). Their average working week comprised $42 \mathrm{~h}$, with an average nursing career of $4 \mathrm{yr}$. Almost all $(92.3 \%)$ were registered nurses, and around half $(49.6 \%)$ worked rotating day and night shifts. Around half $(49.6 \%)$ had received the full three-course Hepatitis B (HB) vaccination regimen, $28.0 \%$ had been vaccinated once or twice, while the remaining $22.4 \%$ reported having received no $\mathrm{HB}$ vaccinations at all.

Likert scale responses to individual safety climate questions are displayed in Fig. 1. Most nurses (94\%) strongly agreed that disposable gloves were readily available in their work area. Around three-quarters also strongly agreed that a copy of the hospital health and safety manual was available in their unit $(77 \%)$ and that protection of workers from blood-borne diseases was a high priority with management (75\%). Over half of all nurses (58\%) agreed that there was minimal conflict in their department. Around $27 \%$ disagreed that they usually have so much work to do that they cannot follow Universal Precautions, while $8 \%$ strongly disagreed with the statement that staff had the opportunity to be trained to use Personal Protective Equipment (PPE) to protect themselves from blood-borne disease exposures. The Cronbach's alpha score for all safety climate questions was 0.906 , indicating a high internal consistency. Likert scale responses to the psychosocial risk factors questions are displayed in Fig. 2. Over half the nurses (56\%) strongly agreed with the statement that there was too much responsibility in their job. Slightly less (41\%) reported that they experienced too much mental pressure at their workplace. Over half (62\%) disagreed with the statement that there was not enough teamwork in their department while 39\% strongly disagreed that their daily work was too boring or tedious. The Cronbach's alpha score for all psychosocial factor questions was 0.887 , indicating a high internal consistency.

The most common types of NSI sustained in the previous 12-month period were due to ampoules or vials (being responsible for $29 \%$ of the total), followed by hollow bore needles (15\%) and insulin syringes (9\%). Ampoules or vials were the most likely to have been unused prior to injury (87\%), followed by hollow bore needles and insulin syringes. Most of the NSI sustained from IV kits (93\%) involved unused items. The prior usage status of butterfly needles was unknown in the majority of cases. The most common cause of single injury in the current study (90\%) was due to IV kits, followed by glass items $(75 \%)$ or insulin syringes $(71 \%)$.
Around half (48\%) of all ampoule or vial NSI involved 2 to 3 injuries. Only $10 \%$ of all NSI due to IV kits involved 2 to 3 injuries. The most common cause of multiple NSI among nurses, that is sustaining 4 or more injuries over the past 12-month, was related to the use of surgical tools (14\%) and ampoules or vials (13\%). Refer to Table 1. Regarding the action which caused the nurse's NSI, over half $(59 \%)$ involved opening an ampoule or vial, $9 \%$ were sustained when uncapping a needle, $7 \%$ due to recapping, $7 \%$ due to other reasons and $6 \%$ were caused by handling a broken ampoule or vial. Only $25.5 \%$ of nurses had always reported to management any NSI they sustained, with $64.1 \%$ never reporting it and $10.4 \%$ reporting it sometimes. The most common reason was that the item was unused (57\%). Thirteen percent did not know they had to report it, $5 \%$ were too busy to report it and $4 \%$ were too embarrassed at their mistake. Interestingly, $2 \%$ felt they were 'not unlucky enough to get a disease'.

Chi-squared analysis revealed various statistically-significant relationships between the HSCS and the type of NSI device which caused injury. Relationships with all devices were analysed, except for lumbar punch kits and razors, due to low response rates for these particular items. NSI due to butterfly needles was related to staff supporting one another at work $(p=0.014)$. NSI due to blood collection tubes was correlated with three HSCS questions, namely the protection of staff against blood-borne disease exposures being a high management priority $(p=0.008)$, managers doing their part to protect staff from bloodborne disease exposures $(p=0.024)$ and unsafe work practices being corrected by supervisors $(p=0.043)$. NSI from surgical tools was correlated with having a clean work area $(p=0.030)$. NSI from suture needles was statistically correlated with managers doing their part to protect staff from blood-borne disease exposures $(p=0.002)$, having the opportunity to be trained to use safety equipment to protect against blood-borne disease exposures $(p=0.026)$, having a clean work area $(p<0.001)$, having an uncluttered work area $(p<0.001)$ and having minimal conflict within their department $(p=0.007)$. The category 'Other Items' was related to having an uncluttered work area $(p=0.007)$. Refer to Table 2 .

\section{Discussion}

The nurses in our current study exhibited many demographic attributes similar to those in some recent national investigations ${ }^{36,37)}$. Results from our current study offer an interesting insight into the safety climate of Japanese hospitals. Most nurses strongly agreed that disposable gloves were readily available in their work area, approximately three-quarters strongly agreed that a copy 


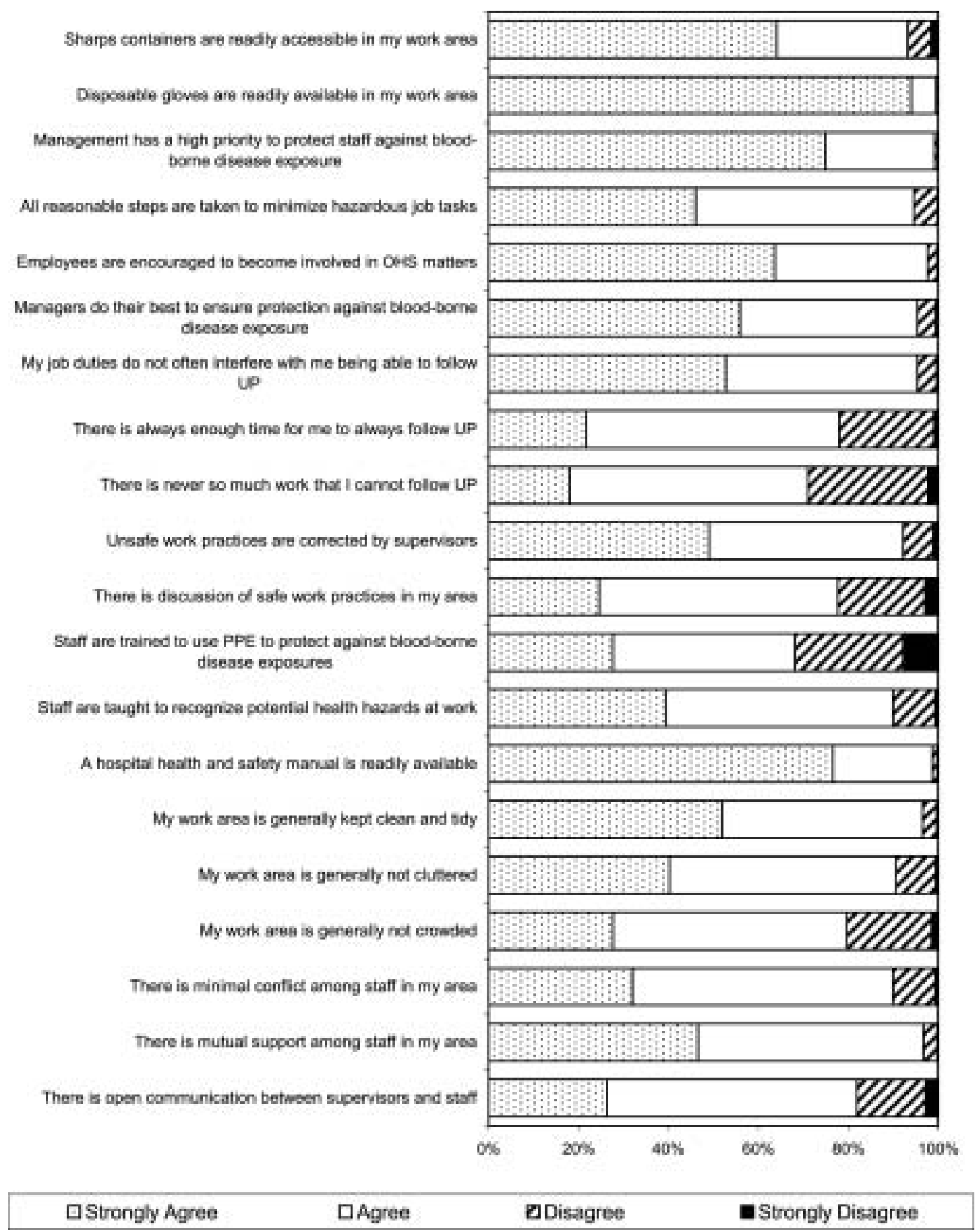

Fig. 1. Likert scale responses to Hospital Safety Climate Scale questions.

Note: Displayed as the proportion of all responses for each question. Hospital Safety Climate Scale translated and adapted from Gershon et $a l^{23)}$, UP = Universal Precautions, OHS = Occupational Health and Safety, Cronbach's alpha score $=0.906$.

of the health and safety manual was available in their unit and that protection of workers from blood-borne diseases was a high priority with management. These findings are similar to the original HSCS study conducted by Gershon and colleagues in $2000^{23)}$, where $94 \%$ reported that disposable gloves were readily available, $95 \%$ agreed that a health and safety manual was available and $85 \%$ agreed that protection from HIV was a high priority with management. The internal consistency of our Japanese HSCS and psychosocial factor questions was demonstrated with high Cronbach's alpha scores; scores that were even higher than some previous research using different safety cli- 


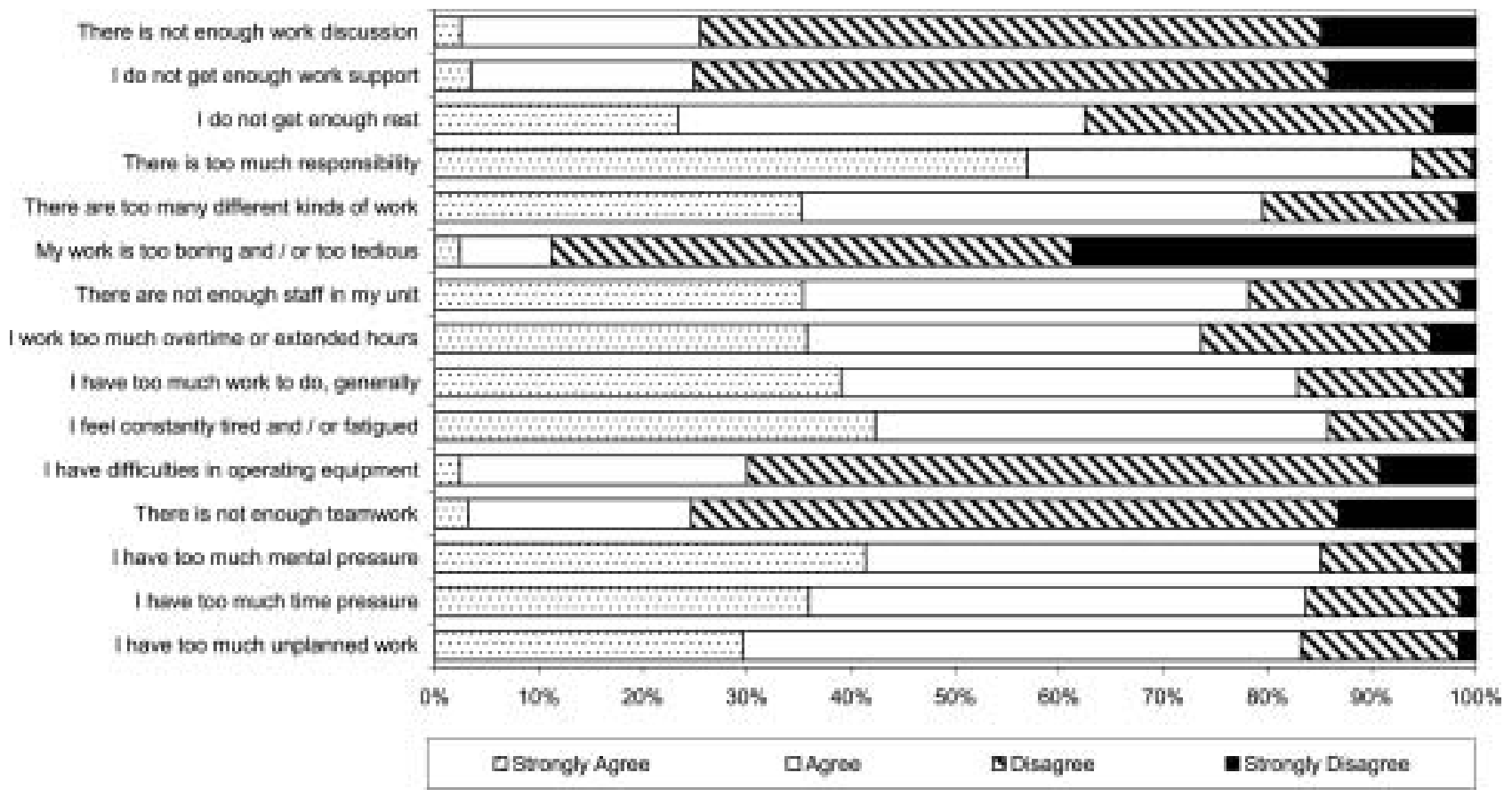

Fig. 2. Likert scale responses to psychosocial risk factor questions.

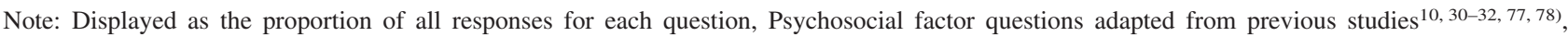
Cronbach's alpha score $=0.887$

Table 1. Needlestick and sharps injuries by causative device, number of injuries and prior usage status

\begin{tabular}{lcccrrr}
\hline & \multicolumn{3}{c}{ Number of Injuries* } & \multicolumn{3}{c}{ Prior Usage Status* } \\
\cline { 2 - 6 } Causative Device & Only 1 & 2 or 3 & 4 or More & Yes & No & Not Sure \\
\hline IV Kit & $90 \%$ & $10 \%$ & $0 \%$ & $2 \%$ & $93 \%$ & $5 \%$ \\
Other Item & $75 \%$ & $17 \%$ & $8 \%$ & $7 \%$ & $80 \%$ & $13 \%$ \\
Insulin Syringe & $71 \%$ & $29 \%$ & $0 \%$ & $16 \%$ & $79 \%$ & $5 \%$ \\
Glass Item & $71 \%$ & $21 \%$ & $7 \%$ & $6 \%$ & $87 \%$ & $6 \%$ \\
Suture Needle & $67 \%$ & $27 \%$ & $6 \%$ & $13 \%$ & $82 \%$ & $5 \%$ \\
Blood Collection Tube & $59 \%$ & $41 \%$ & $0 \%$ & $11 \%$ & $85 \%$ & $4 \%$ \\
Butterfly Needle & $58 \%$ & $42 \%$ & $0 \%$ & $9 \%$ & $86 \%$ & $5 \%$ \\
Hollow Bore Needle & $57 \%$ & $37 \%$ & $6 \%$ & $9 \%$ & $88 \%$ & $3 \%$ \\
Surgical Tool & $57 \%$ & $29 \%$ & $14 \%$ & $11 \%$ & $86 \%$ & $3 \%$ \\
Ampoule/Vial & $39 \%$ & $48 \%$ & $13 \%$ & $9 \%$ & $87 \%$ & $4 \%$ \\
\hline
\end{tabular}

*As a proportion of each total.

mate scales in health care ${ }^{38)}$. Cronbach's alpha scores for the original English-language version of the HSCS by Gershon and colleagues were between 0.71 and $0.84^{23}$. Given that our questionnaire was originally adapted from another language, it is important to keep cross-cultural differences in mind when comparing the results of different studies. Although international research conducted across a variety of countries has suggested that workplace stressors, ways of coping and levels of physical and mental health may be similar ${ }^{39}$, the accurate translation and interpretation of results is always essential, as Japanese are known to respond differently to question- naires translated from English ${ }^{40)}$.

When considering responses to the psychosocial factors questions, over half the nurses strongly agreed with the statement that there was too much responsibility in their job, while slightly fewer reported that they experienced too much mental pressure at work. Mental stress is an important issue in contemporary occupational health and one that has been receiving increasing attention in Japan during recent years. Potentially high rates of psychosocial stresses suggested in the current study are supported by previous research which found that depressive symptoms affected around $28 \%$ of Japanese medical resi- 
dents ${ }^{41)}$. Another study of medical residents also found that depressive symptoms were associated with NSI events ${ }^{13)}$, while a Korean investigation revealed that HCW who had sustained an NSI experienced higher scores of depression and anxiety ${ }^{42)}$. In the US, $15 \%$ of non hospital-based nurses reported being very adversely affected by environmental conditions at their workplace, with understaffing and feeling unappreciated being the most troubling6). Such findings help shed light on psychosocial risk factors as an increasing challenge for $\mathrm{HCW}$ in the new millennium ${ }^{43}$, and for these reasons, it is becoming increasingly clear that more attention needs to be directed towards holistic stress reduction techniques in the workplace.

Regarding NSI themselves, the most common causative devices revealed in the current study were ampoules or vials, followed by hollow bore needles and insulin syringes. These findings are somewhat consistent with other NSI research conducted in Japan. An analysis of Exposure Prevention Information Network (EPINet) data between 1996 and 1998 for example ${ }^{44)}$, found that syringes and butterfly needles were the most common causative device, similar to a later study of EPINet data between 1997 and 200425). Another Japanese study conducted in 2004 also found that ampoules or vials, hollow bore needles and insulin needles were common causes of $\mathrm{NSI}^{10)}$. Similar to Japan, research from Turkey9), Australia $^{35)}$, Singapore ${ }^{45)}$, Taiwan ${ }^{33)}$, Saudi Arabia ${ }^{46)}$ and Korea ${ }^{12)}$ has indicated that disposable syringes and medication ampoules continue to present NSI risks for HCW. Butterfly needles were also a reasonably common cause of NSI in the current study, although this is not surprising, because butterfly needles are used much more frequently for blood drawing and IV infusion in Japan, than in other countries such as the US ${ }^{44)}$. Although it has been previously reported that the injury rate for injection pens is considerably higher than for disposable syringes ${ }^{47)}$, we did not investigate this particular item in our current study.

Regarding prior usage status, ampoules or vials were the most likely to have been unused prior to injury. This finding is similar to previous research conducted among Taiwanese $\mathrm{HCW}^{33}$ ). Most of the NSI sustained from IV kits involved unused items, which is contrary to some earlier Japanese EPINet information ${ }^{44)}$. The prior usage status of butterfly needles was unknown in the majority of cases during the current study. The most common cause of single injuries among our Japanese nurses were NSI due to IV kits, followed by other items, glass items or insulin syringes. Around half of all ampoule or vial NSI involved two to three injuries. The most common cause of multiple NSI among nurses, was related to the use of surgical tools. The finding that surgery was a common cause of repeated NSI is consistent with previous reports ${ }^{48)}$, with an Iranian study further demonstrating that suturing was one of the most common causes of exposures $^{49)}$. Opening an ampoule or vial was a common cause of NSI in the current study, although uncapping and recapping needles also contributed. The recapping of used needles remains a contentious issue in health care, and although it is becoming rarer in most countries, the practice has not altogether disappeared. In Egypt, for example, Talaat et al. ${ }^{50)}$ reported that two-handed recapping was the most common behaviour associated with NSI, similar to a Taiwanese investigation ${ }^{33)}$; while in Turkey ${ }^{51)}$ and China ${ }^{52)}$ it was the second most common cause. In a study from sub-Saharan Africa, HCW who recapped needles 'most of the time' incurred an almost two-fold higher NSI risk ${ }^{53)}$.

Only one-quarter of nurses in the current study had always reported to management any NSI they sustained. The main reasons for not reporting their NSI was that the item was unused. This result is similar to some previous research conducted in Taiwan ${ }^{34)}$, where around one-third of injured HCW did not report their NSI as the item was unused. Interestingly, a small proportion of nurses who sustained an NSI did not report their injury because they felt they were 'not unlucky enough to get a disease'. This finding is similar to some previous research conducted in Taiwan $^{34)}$, where $5 \%$ of injured HCW felt that they were not so unfortunate as to contract a disease. Whatever their rationale may be, the underreporting of NSI remains a serious issue for infection control managers and NSI researchers, given that underreporting rates have been previously documented at $85 \%$ in Taiwan ${ }^{34)}$ and $49 \%$ in the United Kingdom $(\mathrm{UK})^{54)}$. A literature review of online databases in the UK also found that the NSI underreporting rate may be as high as ten-fold ${ }^{55}$.

An examination of HSCS responses by NSI device revealed some interesting correlations. These issues raise a broader question regarding the value of a positive work environment for staff in Japan, as elsewhere. Although the rationale and general principles for improving a worker's emotional climate were recognised early on in occupational health ${ }^{56)}$, further work still needs to be undertaken with a more specific focus on NSI. In this regard it has already been suggested that further research should now be considered with regard to the specific psychological consequences of NSI in $\mathrm{HCW}^{42)}$. Although the complicity of psychosocial risk factors is now well-known in occupational health, it appears that this issue had been studied among Asian nurses until 200457). Given that the vast majority of nurses in the current study were female, it is also important to recognise the unique issues faced by women workers ${ }^{58)}$. The Japanese nursing workforce remains predominately female, and the unique health 


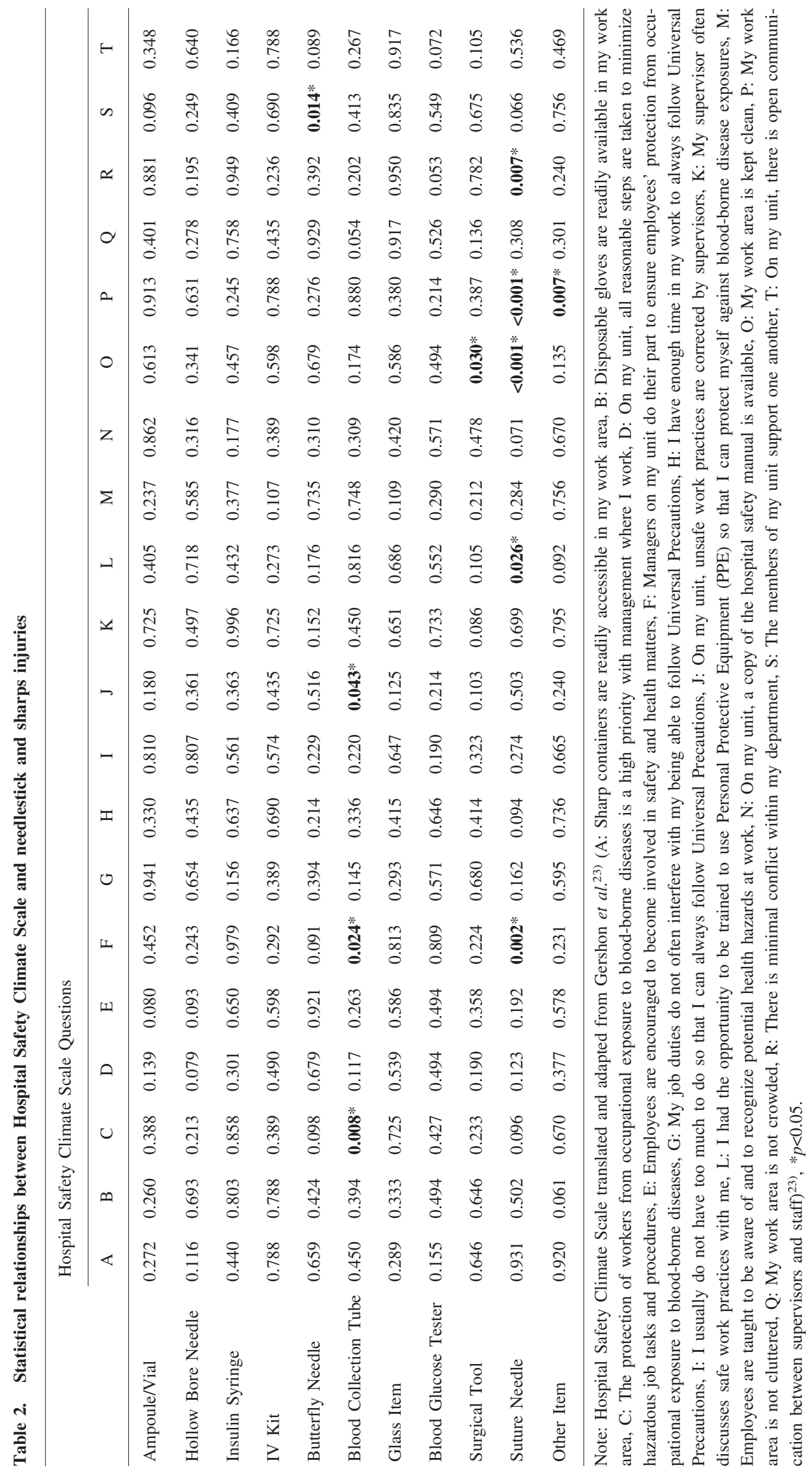


needs of this demographic should be considered. The smaller size of women when compared to men, for example, needs to be carefully considered when working positions and movements are planned ${ }^{59)}$. The complicity of female reproductive health complaints represents another issue in the potential management of psychosocial risk factors ${ }^{60)}$. There are also country-specific NSI issues that should be considered when planning preventive strategies. Japanese employees are known to work long hours ${ }^{61)}$, for example, and long working hours have been shown to be a risk factor for NSI in some studies ${ }^{62)}$. At least part of any potential NSI management strategy will need to consider these issues.

As we pass through our first decade of the 21th century, and despite considerable attention and resources being dedicated to its prevention, NSI and other percutaneous injuries remain common in health care ${ }^{51)}$. While the use of safer devices is no doubt important, many other factors also affect NSI rates. Workplace issues may contribute to risk, with hospital profitability for example being inversely related to blood and body fluid exposure in some studies ${ }^{63)}$, as too, duration into shift ${ }^{64)}$ and month of the year ${ }^{65)}$. Understaffing may be a risk factor for occupationally-related $\mathrm{HCV}^{66}$ ). Undesirable organizational factors, broadly, are often correlated with increased injury risk in health care ${ }^{67)}$, and for NSI specifically, staffing levels and organizational climate are known to be important. At its broadest level, mental health status is known to be an important predictor of occupational accidents in Japanese hospitals ${ }^{68)}$, while personality and behaviour has also been shown to have a relationship with occupational blood exposure in France ${ }^{69}$. Prevention of NSI by the use of safer devices therefore, remains very important and must always be considered in primary management strategies.

When considering the reduction and prevention of NSI within hospital environments, the most direct way to reduce injuries is to make devices safer ${ }^{70)}$. Various investigations have already shown that using safer devices can help reduce injuries in this manner. A previous study in Scotland for example ${ }^{71)}$, reported that over half of all injuries might have been prevented via the use of safety devices. In a US hospital, the introduction in safety-engineered devices was also correlated with an overall decrease in percutaneous injuries ${ }^{72)}$. Furthermore, in a recent Taiwanese study, educational intervention was shown to reduce the incidence of NSI and increase the reporting rate among student nurses ${ }^{73)}$. Checklists to aid in the prevention of NSI are important and have already been trialled in Japan. In 2006 for example, Yoshikawa et $a{ }^{74)}$ designed an ergonomic checklist for training in the prevention of NSI. Aside from safer systems and devices, the collection of accurate data is known to rep- resent another essential component for reducing $\mathrm{NSI}^{75}$, and for these reasons, the regular epidemiological investigation of these issues must continue within health care facilities. Continued epidemiological surveillance is also very important for understanding where, when and how NSI are occurring. EPINet for example, was introduced to Japan during the $1990 \mathrm{~s}^{76}$, and has since been providing a wealth of data on NSI within Japanese hospitals.

The design and use of culturally-appropriate survey tools to investigate NSI and safety climate remains a contentious issue when conducting cross-cultural research. The safety climate phase of our current study used a Japanese translated version of Gershon and colleagues' $\mathrm{HSCS}^{23)}$, for a variety of reasons. Firstly, the basic instrument in English has already been shown to have sufficient reliability and validity as an indicator of employee perceptions of safety within their institution ${ }^{24)}$. Secondly, the HSCS tool itself is simple and convenient to administer, containing only 20 questions in a simple Likert scale format. This makes it more straightforward to understand and complete. Our Japanese-language version was specifically designed and tested during the pilot phase for ease of understanding and ease of completion. The high proportion of staff who 'strongly agreed' that disposable gloves were readily available (a known fact), suggests that our HSCS questionnaire was logical, well-understood and truthfully answered. Questions relating to psychosocial factors were adapted from common elements revealed in a variety of international studies ${ }^{30-32)}$, research which suggests that there is probably a core group of psychosocial risk factors common around the world. Some previous Japanese studies have also investigated these issues ${ }^{77,78)}$, leading us to adopt a core group of 15 questions which were translated and subsequently used. No method will ever be perfect for all cultures and languages, however, and it is important to recognise the limitations of using translated instruments.

\section{Conclusions}

Overall, this study suggests that hospital safety climate represents an important influence in Japanese health care practice. Not all safety climate factors were related to NSI however, and similarly, not all NSI devices were associated with all aspects of safety climate. These findings indicate, therefore, that NSI and safety climate interactions are both complicated and multifaceted in Japanese health care environments. Various limitations of the current study include generalizability due to the inclusion of only one hospital, the cross-sectional nature of data collection which made it difficult to establish causal links, the difficulty in conducting more advanced data analysis, and fact that many different types of safety climate ques- 
tionnaire exist. On the other hand our investigation benefited from many strengths, including a large sample size, high response rate, high internal validity, as well as the practicality of employing a questionnaire known to be useful in the health care field. Although the provision of safer devices remains critical in preventing injuries, ensuring a positive safety climate will also be essential in meeting these important challenges for nurses' occupational health in Japan, as elsewhere.

\section{References}

1) Leggat PA, Smith DR (2006) Prevalence of percutaneous exposure incidents amongst dentists in Queensland. Aust Dent J 51, 158-61.

2) Puro V, de Carli G, Petrosillo N, Ippolito G (2001) Risk of exposure to bloodborne infection for Italian healthcare workers, by job category and work area. Studio Italiano Rischio Occupazionale da HIV Group. Infect Control Hosp Epidemiol 22, 206-10.

3) Smith DR, Leggat PA (2005) Needlestick and sharps injuries among nursing students. J Adv Nurs 51, 449-55.

4) Leggat PA (1987) Microbiological hazards posed by 'sharps': complications of needle puncture injuries to nurses. Aust Microbiologist 8, 311-4.

5) Smith DR, Wei N, Wang RS (2004) Needlesticks and sharps injuries among Chinese hospital nurses. Adv Exp Prev 7, 11-2.

6) Gershon RR, Qureshi KA, Pogorzelska M, Rosen J, Gebbie KM, Brandt-Rauf PW, Sherman MF (2007) Non-hospital based registered nurses and the risk of bloodborne pathogen exposure. Ind Health 45, 695-704.

7) Shiao J, Guo L, McLaws ML (2002) Estimation of the risk of bloodborne pathogens to health care workers after a needlestick injury in Taiwan. Am J Infect Control 30, 15-20.

8) Kiyosawa K, Sodeyama T, Tanaka E, Nakano Y, Furuta S, Nishioka K, Purcell RH, Alter HJ (1991) Hepatitis $\mathrm{C}$ in hospital employees with needlestick injuries. Ann Intern Med 115, 367-9.

9) Ayranci U, Kosgeroglu N (2004) Needlestick and sharps injuries among nurses in the healthcare sector in a city of western Turkey. J Hosp Infect 58, 216-23.

10) Smith DR, Mihashi M, Adachi $Y$, Nakashima $Y$, Ishitake $\mathrm{T}$ (2006) Epidemiology of needlestick and sharps injuries among nurses in a Japanese teaching hospital. J Hosp Infect 64, 44-9.

11) Smith DR, Mihashi M, Adachi Y, Shouyama Y, Mouri F, Ishibashi N, Ishitake T (2009) Organizational climate and its relationship with needlestick and sharps injuries among Japanese nurses. Am J Infect Control 37, 545-50.

12) Smith DR, Choe MA, Jeong JS, Jeon MY, Chae YR, An GJ (2006) Epidemiology of needlestick and sharps injuries among professional Korean nurses. J Prof Nurs
22, 359-66.

13) Wada K, Sakata Y, Fujino Y, Yoshikawa T, Tanaka K, Miyajima E, Watanabe M, Aizawa Y (2007) The association of needlestick injury with depressive symptoms among first-year medical residents in Japan. Ind Health 45, 750-5.

14) Gershon RR, Stone PW, Zeltser M, Faucett J, MacDavitt K, Chou SS (2007) Organizational climate and nurse health outcomes in the United States: a systematic review. Ind Health 45, 622-36.

15) Grosch JW, Gershon RR, Murphy LR, DeJoy DM (1999) Safety climate dimensions associated with occupational exposure to blood-borne pathogens in nurses. Am J Ind Med 1 (Suppl), 122-4.

16) Kudo Y, Satoh T, Kido S, Watanabe M, Miki T, Miyajima E, Saegusa Y, Tsunoda M, Aizawa Y (2008) A pilot study testing the dimensions of safety climate among Japanese nurses. Ind Health 46, 158-65.

17) Kudo Y, Kido S, Taruzuka Shahzad M, Saegusa Y, Satoh T, Aizawa Y (2009) Safety climate and motivation toward patient safety among Japanese nurses in hospitals of fewer than 250 beds. Ind Health 47, 70-9.

18) Baek JB, Bae S, Ham BH, Singh KP (2008) Safety climate practice in Korean manufacturing industry. $\mathrm{J}$ Hazard Mater 159, 49-52.

19) Flin R, Mearns K, O'Connor P, Bryden R (2000) Measuring safety climate: Identifying the common features. Saf Sci 34, 177-92.

20) Colla JB, Bracken AC, Kinney LM, Weeks WB (2005) Measuring patient safety climate: a review of surveys. Qual Saf Health Care 14, 364-6.

21) Flin R, Burns C, Mearns K, Yule S, Robertson EM (2006) Measuring safety climate in health care. Qual Saf Health Care 15, 109-15.

22) Singla AK, Kitch BT, Weissman JS, Campbell EG (2006) Assessing patient safety culture: a review and synthesis of the measurement tools. J Patient Saf 2, 105-15.

23) Gershon RR, Karkashian CD, Grosch JW, Murphy LR, Escamilla-Cejudo A, Flanagan PA, Bernacki E, Kasting C, Martin L (2000) Hospital safety climate and its relationship with safe work practices and workplace exposure incidents. Am J Infect Control 28, 211-21.

24) Turnberg W, Daniell W (2008) Evaluation of a healthcare safety climate measurement tool. J Safety Res 39, 563-8.

25) Nagao Y, Baba H, Torii K, Nagao M, Hatakeyama K, Iinuma Y, Ichiyama S, Shimokata K, Ohta M (2007) A long-term study of sharps injuries among health care workers in Japan. Am J Infect Control 35, 407-11.

26) Yoshikawa T, Kidouchi K, Kimura S, Okubo T, Perry J, Jagger J (2007) Needlestick injuries to the feet of Japanese healthcare workers: a culture-specific exposure risk. Infect Control Hosp Epidemiol 28, 215-8.

27) Likert $R$ (1932) A technique for the measurement of attitudes. Archives of Psychology 140, 1-55.

28) Lee JW, Jones PS, Mineyama Y, Zhang XE (2002) 
Cultural differences in responses to a Likert scale. Res Nurs Health 25, 295-306.

29) Chen C, Lee SY, Stevenson HW (1995) Response style and cross-cultural comparisons of rating scales among East Asian and North American students. Psychol Sci 6, 170-5.

30) Bongers PM, de Winter CR, Kompier MA, Hildebrandt VH (1993) Psychosocial factors at work and musculoskeletal disease. Scand J Work Environ Health 19, 297-312.

31) Bongers PM, Ijmker S, van den Heuvel S, Blatter BM (2006) Epidemiology of work related neck and upper limb problems: psychosocial and personal risk factors (part I) and effective interventions from a bio behavioural perspective (part II). J Occup Rehabil 16, 279-302.

32) Bongers PM, Kremer AM, ter Laak J (2002) Are psychosocial factors, risk factors for symptoms and signs of the shoulder, elbow, or hand/wrist?: a review of the epidemiological literature. Am J Ind Med 41, 315-42.

33) Guo YL, Shiao J, Chuang YC, Huang KY (1999) Needlestick and sharps injuries among health-care workers in Taiwan. Epidemiol Infect 122, 259-65.

34) Shiao JS, McLaws ML, Huang KY, Ko WC, Guo YL (1999) Prevalence of nonreporting behavior of sharps injuries in Taiwanese health care workers. Am J Infect Control 27, 254-7.

35) Smith DR, Smyth W, Leggat PA, Wang RS (2006) Needlestick and sharps injuries among nurses in a tropical Australian hospital. Int J Nurs Pract 12, 71-7.

36) Fujita $T$, Hayashi K, Katanoda K, Matsumura Y, Lee JS, Takagi H, Suzuki S, Mizunuma H, Aso T (2007) Prevalence of diseases and statistical power of the Japan Nurses' Health Study. Ind Health 45, 687-94.

37) Hayashi K, Mizunuma H, Fujita T, Suzuki S, Imazeki S, Katanoda K, Matsumura Y, Kubota T, Aso T (2007) Design of the Japan nurses' health study: a prospective occupational cohort study of women's health in Japan. Ind Health 45, 679-86.

38) Kho ME, Carbone JM, Lucas J, Cook DJ (2005) Safety climate survey: reliability of results from a multicenter ICU survey. Qual Saf Health Care 14, 273-8.

39) Lambert VA, Lambert CE, Itano J, Inouye J, Kim S, Kuniviktikul W, Sitthimongkol Y, Pongthavornkamol K, Gasemgitvattana S, Ito M (2004) Cross-cultural comparison of workplace stressors, ways of coping and demographic characteristics as predictors of physical and mental health among hospital nurses in Japan, Thailand, South Korea and the USA (Hawaii). Int J Nurs Stud 41, 671-84.

40) Otsuka Y, Takada M, Suzuki A, Tomotake S, Nakata A (2008) The Japanese version of the coping orientation to problems experienced: a study of Japanese schoolteachers. Psychol Rep 103, 395-405.

41) Sakata $Y$, Wada K, Tsutsumi A, Ishikawa H, Aratake Y, Watanabe M, Katoh N, Aizawa Y, Tanaka K (2008) Effort-reward imbalance and depression in Japanese medical residents. J Occup Health 50, 498-504.

42) Sohn JW, Kim BG, Kim SH, Han C (2006) Mental health of healthcare workers who experience needlestick and sharps injuries. J Occup Health 48, 474-9.

43) Smith DR, Leggat PA, Araki S (2007) Emerging occupational hazards among health care workers in the new millennium. Ind Health 45, 595-7.

44) Jagger J, Parker G, Perry J (2002) Japanese-US collaborative program: sharing data, learning lessons. Adv Exp Prev 6, 3-5.

45) Ng LN, Lim HL, Chan YH, Bin Bachok D (2002) Analysis of sharps injury occurrences at a hospital in Singapore. Int J Nurs Pract 8, 274-81.

46) Memish ZA, Almuneef M, Dillon J (2002) Epidemiology of needlestick and sharps injuries in a tertiary care center in Saudi Arabia. Am J Infect Control 30, 234-41.

47) Pellissier G, Migueres B, Tarantola A, Abiteboul D, Lolom I, Bouvet E (2006) Risk of needlestick injuries by injection pens. J Hosp Infect 63, 60-4.

48) Tokars JI, Bell DM, Culver DH, Marcus R, Mendelson MH, Sloan EP, Farber BF, Fligner D, Chamberland ME, McKibben PS, Martone WI (1992) Percutaneous injuries during surgical procedures. JAMA 267, 2899-904.

49) Shariati B, Shahidzadeh-Mahani A, Oveysi T, Akhlaghi $\mathrm{H}$ (2007) Accidental exposure to blood in medical interns of Tehran University of Medical Sciences. J Occup Health 49, 317-21.

50) Talaat M, Kandeel A, El-Shoubary W, Bodenschatz C, Khairy I, Oun S, Mahoney FJ (2003) Occupational exposure to needlestick injuries and hepatitis B vaccination coverage among health care workers in Egypt. Am J Infect Control 31, 469-74.

51) Kuruuzum Z, Yapar N, Avkan-Oguz V, Aslan H, Ozbek OA, Cakir N, Yuce A (2008) Risk of infection in health care workers following occupational exposure to a noninfectious or unknown source. Am J Infect Control 36, e27-31.

52) Phipps W, Honghong W, Min Y, Burgess J, Pellico L, Watkins CW, Guoping H, Williams A (2002) Risk of medical sharps injuries among Chinese nurses. Am J Infect Control 30, 277-82.

53) Nsubuga FM, Jaakkola MS (2005) Needle stick injuries among nurses in sub-Saharan Africa. Trop Med Int Health 10, 773-81.

54) Elmiyeh B, Whitaker IS, James MJ, Chahal CA, Galea A, Alshafi K (2004) Needle-stick injuries in the National Health Service: a culture of silence. J R Soc Med 97, 326-7.

55) Elder A, Paterson C (2006) Sharps injuries in UK health care: a review of injury rates, viral transmission and potential efficacy of safety devices. Occup Med (Lond) 56, 566-74.

56) MacPherson AS (1966) Improving the worker's emotional environment. Ind Med Surg 35, 259-61.

57) Smith DR, Wei N, Zhao L, Wang RS (2004) 
Musculoskeletal complaints and psychosocial risk factors among Chinese hospital nurses. Occup Med (Lond) 54, 579-82.

58) Smith DR (2008) Menstrual disorders and their adverse symptoms at work: an emerging occupational health issue in the nursing profession. Nurs Health Sci 10, 222-8.

59) Forssman S (1964) Women at work: health and sociomedical problems related to the employment of women. Ind Med Surg 33, 125-9.

60) Smith DR, Mihashi M, Adachi Y, Shouyama Y, Mouri F, Ishibashi N, Ishitake T (2009) Menstrual disorders and their influence on low back pain among Japanese nurses. Ind Health 47, 301-12.

61) Otsuka Y, Sasaki T, Iwasaki K, Mori I (2009) Working hours, coping skills, and psychological health in Japanese daytime workers. Ind Health 47, 22-32.

62) Ilhan MN, Durukan E, Aras E, Turkcuoglu S, Aygun R (2006) Long working hours increase the risk of sharp and needlestick injury in nurses: the need for new policy implication. J Adv Nurs 56, 563-8.

63) Stone PW, Gershon RR (2006) Nurse work environments and occupational safety in intensive care units. Policy Polit Nurs Pract 7, 240-7.

64) Macias DJ, Hafner J 2nd, Brillman JC, Tandberg D (1996) Effect of time of day and duration into shift on hazardous exposures to biological fluids. Acad Emerg Med 3, 605-10.

65) Hsieh WB, Chiu NC, Lee CM, Huang FY (2006) Occupational blood and infectious body fluid exposures in a teaching hospital: a three-year review. J Microbiol Immunol Infect 39, 321-7.

66) Petrosillo N, Gilli P, Serraino D, Dentico P, Mele A, Ragni P, Puro V, Casalino C, Ippolito G (2001) Prevalence of infected patients and understaffing have a role in hepatitis $\mathrm{C}$ virus transmission in dialysis. Am J Kidney Dis 37, 1004-10.

67) Gimeno D, Felknor S, Burau KD, Delclos GL (2005) Organisational and occupational risk factors associated with work related injuries among public hospital employees in Costa Rica. Occup Environ Med 62, $337-43$.

68) Suzuki K, Ohida T, Kaneita Y, Yokoyama E, Miyake T, Harano S, Yagi Y, Ibuka E, Kaneko A, Tsutsui T,
Uchiyama M (2004) Mental health status, shift work, and occupational accidents among hospital nurses in Japan. J Occup Health 46, 448-54.

69) Rabaud C, Zanea A, Mur JM, Blech MF, Dazy D, May T, Guillemin F (2000) Occupational exposure to blood: search for a relation between personality and behavior. Infect Control Hosp Epidemiol 21, 564-74.

70) Jagger JC (2002) Are Australia's healthcare workers stuck with inadequate needle protection? The most direct way to reduce percutaneous injuries is to make devices safer. Med J Aust 177, 405-6.

71) Cullen BL, Genasi F, Symington I, Bagg J, McCreaddie M, Taylor A, Henry M, Hutchinson SJ, Goldberg DJ (2006) Potential for reported needlestick injury prevention among healthcare workers through safety device usage and improvement of guideline adherence: expert panel assessment. J Hosp Infect 63, 445-51.

72) Sohn S, Eagan J, Sepkowitz KA (2004) Safety-engineered device implementation: does it introduce bias in percutaneous injury reporting? Infect Control Hosp Epidemiol 25, 543-7.

73) Yang YH, Liou SH, Chen CJ, Yang CY, Wang CL, Chen CY, Wu TN (2007) The effectiveness of a training program on reducing needlestick injuries/sharp object injuries among soon graduate vocational nursing school students in southern Taiwan. J Occup Health 49, 424-9.

74) Yoshikawa T, Ito A, Sakai K, Kogi K (2006) How to design a practical action checklist for preventing needlestick injuries among health care workers. J UOEH 28 (Suppl), 63-8.

75) Fletcher CE (2000) Accurate data: an essential component in reducing needlestick injuries. Policy Polit Nurs Pract 1, 316-24.

76) Hosomi Y (1997) EPINet 1. Infect Control 6, 99-106 (in Japanese).

77) Ando S, Ono Y, Shimaoka M, Hiruta S, Hattori Y, Hori F, Takeuchi Y (2000) Associations of self estimated workloads with musculoskeletal symptoms among hospital nurses. Occup Environ Med 57, 211-6.

78) Smith DR, Mihashi M, Adachi $Y$, Koga H, Ishitake T (2006) A detailed analysis of musculoskeletal disorder risk factors among Japanese nurses. J Safety Res 37, 195-200. 